\title{
DIY Maker Electronic Supplies Concession Market in Shenzhen
}

(6) Contributor: Eli Blevis $\rightarrow$ Curator/Editor: Eli Blevis $\rightarrow$ Genre: Maker culture, DIY culture, China

A concession market in Shenzhen, a cornerstone of maker culture in China, sells all manner of electronic parts for small-scale production. For a discussion of these trends, please see: Lindtner, S., Greenspan, A., and Li, D. Designed in Shenzhen: Shanzhai manufacturing and maker entrepreneurs. Proc. of the Fifth Decennial Aarhus Conference on Critical Alternatives. Aarhus Univ. Press, 2015, 85-96; Lindtner, S., Bardzell, S., and Bardzell, J. Reconstituting the utopian vision of making: HCI after technosolutionism. Proc. of CHI '16. ACM, New York, 2016 (Nominated for Best Paper).

DOI: $10.1145 / 2953942$ ○ 2016 ACM 1072-5520/16/07 \$15.00

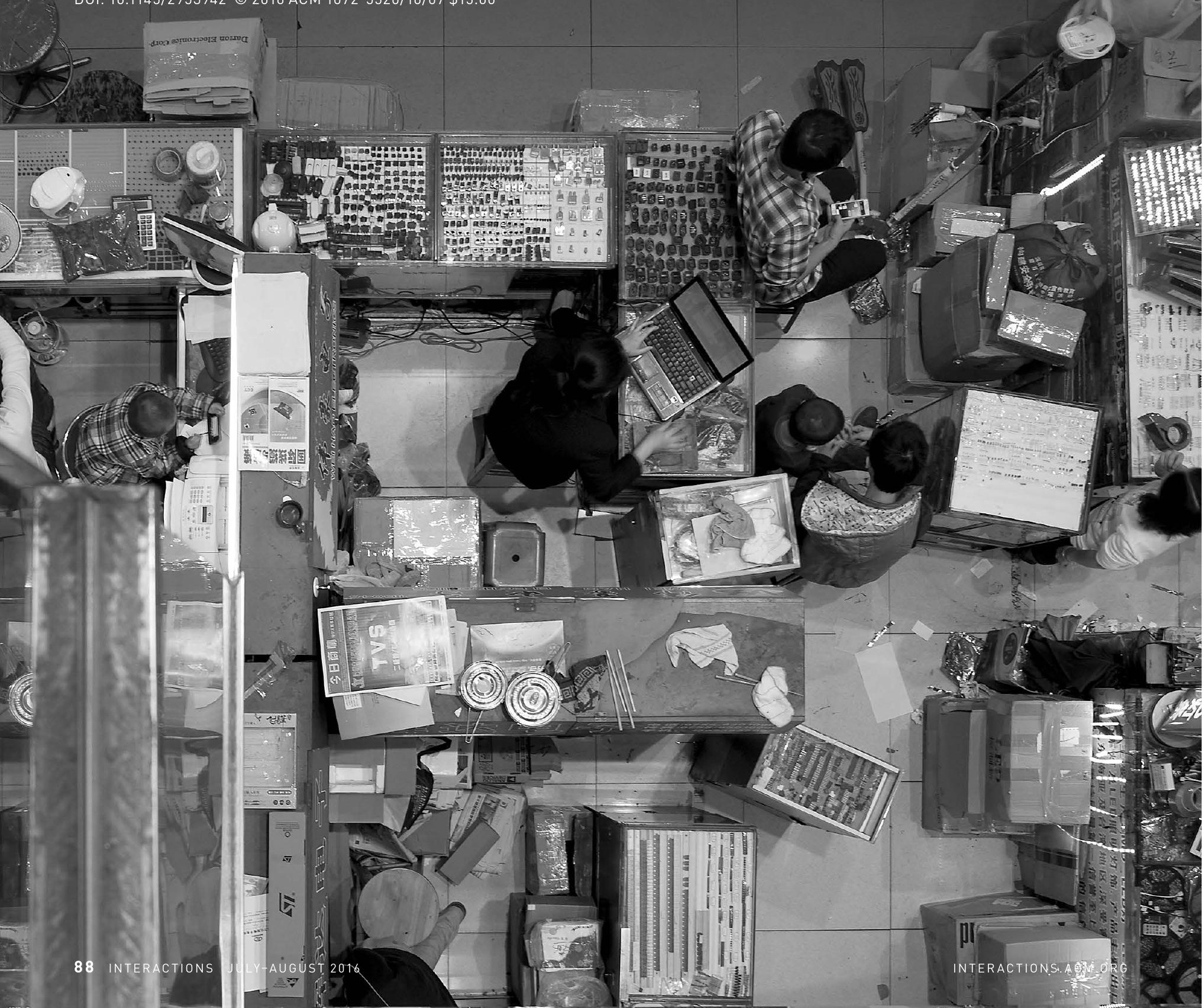

